\title{
Baricitinib and the Risk of Incident Interstitial Lung Disease: A Descriptive Clinical Case Report from Clinical Trials
}

\author{
Carlo Salvarani · Marco Sebastiani · Philippe Dieude · Miriam Garcia • \\ Walter Deberdt · Veronica Rogai · Inmaculada de la Torre • \\ José Inciarte-Mundo · Alejandro Balsa
}

Received: April 9, 2021 / Accepted: June 3, 2021 / Published online: June 28, 2021

(C) The Author(s) 2021

\section{ABSTRACT}

Objectives: Interstitial lung disease (ILD) occurs in up to $30 \%$ of patients with rheumatoid arthritis (RA), resulting in increased morbidity and death in the absence of proven therapies. The aim of this study is to estimate the number of incident ILD cases reported through

C. Salvarani $(\bowtie)$

Rheumatology Unit, Azienda USL-IRCCS di Reggio

Emilia and Università di Modena e Reggio Emilia,

Viale Risorgimento, 80, 42123 Modena, Reggio

Emilia, Italy

e-mail: carlo.salvarani@unimore.it

\section{Sebastiani}

Rheumatology Unit, Department of Surgery, Medicine, Dentistry and Morphological Sciences with Transplant Surgery, Oncology and Regenerative Medicine Relevance, University of Modena and Reggio Emilia, Modena, Italy

\section{P. Dieude}

Department of Rheumatology, DMU Locomotion, INSERM UMR1152, Hôpital Bichat-Claude Bernard, APHP, Université de Paris, Paris, France

M. Garcia - W. Deberdt · V. Rogai · I. de la Torre Eli Lilly and Company, Indianapolis, IN, USA

J. Inciarte-Mundo

Rheumatology Department, Hospital Clinic of Barcelona, IDIBAPS, Barcelona, Spain

\section{A. Balsa}

Rheumatology Department, Hospital La Paz Institute for Health Research (IdiPAZ), Madrid, Spain development studies with baricitinib in patients with RA.

Methods: Estimates were based on 3770 patients with RA from eight randomized clinical trials (four phase 3 , three phase 2 , one phase $1 \mathrm{~b}$ ) and one long-term extension study on baricitinib for which ILD was not an exclusion criterion with 12,358 patient-years of exposure (PYE).

Results: Twenty-one non-infectious cases of ILD were reported with an exposure-adjusted incidence rate (EAIR) of 0.17 per 100 PYE. Of the 21 cases, six were reported as serious and 15 as non-serious resulting in an incidence rate of 0.05 per 100 PYE and 0.12 per 100 PYE, respectively. There were also 11 cases caused by an infectious agent: seven serious (IR: 0.06 per 100 PYE) and four non-serious cases (IR: 0.03 per 100 PYE).

Conclusions: The findings of this analysis in patients with RA treated with baricitinib are consistent with a low risk to develop non-infectious ILD during baricitinib treatment, similar to that observed with other Janus kinase inhibitors.

Keywords: Baricitinib; Interstitial lung disease; Rheumatoid arthritis 


\section{Key Summary Points}

Interstitial lung disease (ILD) prevalence rates in patients with rheumatoid arthritis (RA) are as high as 30\%, resulting in increased mortality rates and morbidity.

Currently, due to a lack of trials, there are no proven therapies effective in preventing RA-ILD development and progression, while the association between baricitinib and ILD is largely unknown.

This work reports on the number of incident ILD cases in 3770 patients with RA across eight clinical trials and one long-term extension study on baricitinib.

Thirty-two cases were reported (21 as noninfectious, six of which were serious and 11 described as caused by an infectious agent, seven of which were serious). These data indicate a low risk to develop noninfectious ILD during baricitinib treatment, similar to that observed with other Janus kinase inhibitors.

\section{DIGITAL FEATURES}

This article is published with digital features, including a summary slide, to facilitate understanding of the article. To view digital features for this article go to https://doi.org/10.6084/ m9.figshare.14725404.

\section{INTRODUCTION}

Rheumatoid arthritis (RA) primarily affects joints, but also presents extra-articular manifestations [1]. Among those manifestations, RAassociated interstitial lung disease (ILD) is the most frequent $[2,3]$. ILD prevalence estimates vary widely between 6 and 30\% of RA patients dependent on studied population, methods and the temporality of screening [1]. Estimations of

ILD incidence rates (either de novo or worsening of an existing condition) in patients with RA range between 0.81 and 6.4 per 1000 person years [4-6].

ILD is one of the leading causes of mortality, contributing approximately to $13 \%$ of RA patients' mortality as compared to the general population $[1,2,4]$ with a threefold higher risk of death for those with ILD than those without. In addition, ILD contributes to a decreased quality of life, progressive chronic disability, and an increased use of healthcare resources.

There have been no trials specifically designed to assess the impact of therapies in ILD progression. High-dose corticosteroids are the first-line treatment, but other traditional immune suppressive drugs, such as azathioprine and cyclophosphamide, are also utilized. Among biologic disease-modifying anti-rheumatic drugs (DMARDs) authorized for the treatment of RA, rituximab has shown some promising positive results in published case series of ILD associated to RA or other connective tissue diseases. A 10-year study showed that rituximab may inhibit the development and progression of ILD [7, 8]. Also, abatacept in a national multicenter, non-controlled, open-label registry study appeared to be safe in RA-associated ILD [9]. Contrasting results were observed for tumor necrosis factor inhibitors (TNFis) $[10,11]$. In some studies, TNFis have been associated with a higher risk of acute exacerbation, while other studies showed that TNFis had the potential to stabilize the progression of pulmonary fibrosis in ILD patients $[10,11]$. Methotrexate exposure was not associated with an increased risk of RA-ILD in a multivariate analysis involving two large cohorts of patients with early RA [12]. On the contrary, the results of this study suggested that MTX may delay the onset of ILD.

Baricitinib is a Janus kinase (JAK) 1 and JAK2 inhibitor approved in over 65 countries for the treatment of moderate-to-severe active RA [13]. The aim of this study is to provide information on incident ILD events presenting with baricitinib treatment for RA during randomized clinical trials and long-term extensions. We focused on ILD non-associated with infectious 
events, however data on ILD reported as caused by infectious agents were also considered.

\section{METHODS}

This descriptive, multicentric, retrospective cohort study included data pooled from eight randomized trials (four phase 3 , three phase 2 , one phase $1 \mathrm{~b}$ ) and one long-term extension study (data up to February 13, 2019), resulting in 3770 patients with RA receiving baricitinib at a variety of doses. The inclusion criteria for the phase 2 and phase 3 (RA-BEGIN, RA-BEAM, RABEACON, RA-BUILD) trials have been described previously [14-17], but briefly, participants were $\geq 18$ years of age and had moderate-tosevere active RA ( $\geq 6$ of 68 tender joints and $\geq 6$ of 66 swollen joints along with a high-sensitivity serum C-reactive protein level $\geq 3 \mathrm{mg} /$ 1). Exclusion criteria included recent serious infection (including active or untreated latent tuberculosis infection) and selected laboratory abnormalities, along with severe nonstable conditions that would put patients at risk during the trial (investigators decision). ILD was not a specific exclusion criterion and investigators did document existing ILD at their discretion. Doses of baricitinib administered ranged from 2 to $8 \mathrm{mg}$ daily ( 2 and $4 \mathrm{mg}$ in phase 3 trials and the long-term extension study). All trials were conducted in accordance with ethical principles of the Declaration of Helsinki and Good Clinical Practice guidelines. All patients provided written informed consent.

Patients were eligible to partake in the longterm extension study upon completion of any of the phase 2 or 3 trials. Extensive information on each of the studies has been previously published [18]. This analysis examines the incidence of ILD cases on patients exposed to baricitinib, further following on from a previous extensive safety report [19]. The clinical and safety databases were searched for the MedDRA narrow preferred terms within the Interstitial Lung Disease Standardised MedDRA Queries (SMQ). The method of ILD diagnosis was reported for serious cases of ILD, with six patients undergoing a CT scan, three an X-ray, and an additional four patients both a CT scan and X-ray. Serious cases were determined by the regulatory definition of fatal, life-threatening, or requiring hospitalization. After ILD classification, we further explored etiology with descriptive purposes.

\section{RESULTS}

In 3770 patients exposed to baricitinib from the investigated trials, there were 32 cases of ILD reported. The time to onset, calculated from the initiation of baricitinib treatment to the onset of the ILD, ranged from 60 to 1740 days (Table 1). All cases were deemed treatmentemergent adverse events defined as incident ILD cases or worsening of the pulmonary condition that was observed in three patients with a reported history of ILD.

Twenty-one cases of ILD not associated with infectious events were reported with an exposure-adjusted incidence rate (EAIR) of 0.17 per 100 patient-years of exposure (PYE). Six of these cases were serious (life-threatening or requiring hospitalization or death) with an incidence rate of 0.05 per 100 PYE, while 15 were non-serious resulting in an EAIR of 0.12 per 100 PYE. Baseline characteristics for patients with non-infectious ILD and serious episodes were similar to those with non-serious episodes including mean age of patients (59.5 years versus 54.7 years) and time from treatment initiation (ranged from 92 days up to 1740 days).

Eleven cases were reported as ILD caused by an infectious agent, seven serious and four nonserious. Non-serious infectious episodes were more common in women, at a younger age, with no previous story of lung disease, and nonsmokers. The characteristics of the patients can be seen in Table 1 .

Of the six patients with serious non-infectious ILD episodes, four resolved upon cessation of the suspected drug and receiving treatment for potential causes of ILD. One patient recovered with sequalae while a further patient died due to acute respiratory syndrome failure. Of the seven patients with serious infection episodes, five resolved upon cessation of the suspect drug and also receiving treatment for 
Table 1 Characteristics of patients and events

\begin{tabular}{llllll}
\hline & \multicolumn{2}{l}{ Non-infectious } & ILD $(\boldsymbol{N}=\mathbf{2 1})$ & & \multicolumn{2}{l}{ Infectious ILD $(\boldsymbol{N}=\mathbf{1 1})$} \\
\cline { 2 - 3 } $\begin{array}{llll}\text { Serious } \\
(\boldsymbol{n}=\mathbf{6})\end{array}$ & $\begin{array}{l}\text { Non-serious } \\
(\boldsymbol{n}=\mathbf{1 5})\end{array}$ & & Serious $(\boldsymbol{n}=7)$ & $\begin{array}{l}\text { Non-serious } \\
(\boldsymbol{n}=\mathbf{4})\end{array}$ \\
\hline EAIR (per 100 PYE) & 0.05 & 0.12 & 0.06 & 0.03 \\
Time from treatment onset, (range) & $92-1540$ days & $121-1740$ days & & 2 months to 3 years & 180 days to 3.5 years \\
Age, mean (range), years & $59.5(48-68)$ & $54.7(31-65)$ & & $64.1(57-75)$ & $48.8(42-53)$ \\
\% male & 50.0 & 40.0 & 57.1 & 25.0 \\
Hospitalization $(n)$ & 5 & 0 & 6 & 0 \\
History of ILD $(n)$ & 1 & 1 & 1 & 0 \\
Current smoker $(n)$ & 0 & 3 & 2 & 0 \\
\hline
\end{tabular}

Data presented as numbers $(n)$ unless stated otherwise

EAIR exposure-adjusted incidence rate, $P Y E$ patient-years of exposure, $I L D$ interstitial lung disease

potential causes of ILD. One patient did not recover and died due to nosocomial infection.

\section{DISCUSSION}

Information regarding the causality of RA treatments and ILD case occurrence is scarce and difficult to interpret. ILD incidence and prevalence increase over time and is a common feature of long-lasting and more severe RA, also with potential casual relationships with other factors including concomitant comorbidities. In this report, we aim to provide information on the incidence rate of ILD as a treatment emergent adverse event (TEAE) and the severity of ILD cases across a number of baricitinib clinical trials, describing those triggered by an infectious agent versus non-infectious etiology. Baricitinib, in a subgroup of RA patients with interstitial lung involvement, has been previously shown to reduce concentration of lung and inflammation biomarkers albeit with a small sample size [20]. In total, across eight studies and 3770 patients, there were 21 cases of non-infectious ILD, with an EAIR of 0.17 per 100 PYE. This is consistent with previous reports estimating an EAIR between 0.81 and 6.4 per 1000 person-years in cohorts of patients with RA treated with different disease-modifying anti-rheumatic drugs [4-6]. Tofacitinib, also an oral Janus kinase inhibitor, reported a similar incidence rate of 0.18 per 100 PYE for non-infectious chronic ILD at both doses of $5 \mathrm{mg}$ and $10 \mathrm{mg}$ daily. In the tofacitinib analysis, the median onset time of ILD from the starting of treatment in RA patients was 1144 days, also comparable with our current analysis (range, 60-1740 days) [21]. JAK inhibition has been associated with infections mainly of the upper respiratory and urinary tract [22]. Confirming the good safety profile of baricitinib, we observed only seven serious cases of ILD caused by an infectious agent.

There are limitations in our study which need to be acknowledged. A lack of uniform diagnostic procedures to better clarify ILD etiology and acute vs. chronic status is relevant, as clinical details relied on investigators diagnosis and evaluation. Further limitations include a lack of baseline characteristic data such as RA duration, history of other extra-articular manifestations along with non-uniform diagnostic methods, and missing methods for non-serious cases. It would also be advantageous to have information about symptoms and specific risk factors, however these data were not available. Among non-infectious ILD, we were also unable to differentiate between acute and chronic interstitial pneumonia to distinguish acute 
hypersensitivity pneumonia from chronic interstitial lung disease. Baricitinib dose ranged between 2 and $8 \mathrm{mg}$ taken daily, however the number of patients in each dosing group did not allow for meaningful dose-response analysis. This analysis is descriptive and only reports the number and corresponding incidence rate of clinical incident ILD cases. We did not perform any statistical analyses or comparisons with other treatments for RA. However, taking into account the number of ILD cases associated with infections, the presence of well-known risk factors for ILD in this specific RA patient population, and the broad range with respect to time of onset following the starting of baricitinib treatment, the current results cannot be used to establish any casual association between baricitinib exposure and development or worsening of non-infectious ILD.

\section{CONCLUSIONS}

In this analysis, patients with RA treated with baricitinib were at low risk of developing ILD during treatment. These results were similar to those observed with other Janus kinase inhibitors.

\section{ACKNOWLEDGEMENTS}

We thank the participants of the study.

Funding. The study and Rapid service Fee were funded by Eli Lilly and Company.

Medical writing/editorial assistance. The authors would like to thank Adam Clooney, PhD, employee of Eli Lilly, for writing and editorial assistance.

Authorship. All named authors meet the International Committee of Medical Journal Editors (ICMJE) criteria for authorship for this article, take responsibility for the integrity of the work as a whole, and have given their approval for this version to be published.
Authors' Contributions. Miriam Garcia, Veronica Rogai, Inmaculada de la Torre: concept, study design, results interpretation and drafting the manuscript Walter Deberdt, Carlo Salvarani, Alejandro Balsa: study design, results interpretation and drafting the manuscript Marco Sebastiani, Philippe Dieude, José Inciarte-Mundo: concept, results interpretation and drafting the manuscript.

Disclosures. Carlo Salvarani: Consultant: Eli Lilly, BMS, Roche, Pfizer, Novartis. Miriam Garcia, Veronica Rogai and Walter Deberdt are employees of Eli Lilly and Company. Inmaculada de la Torre: is an employee and stakeholder of Eli Lilly and Company. Alejandro Balsa: received speaker grants and honoraria from AbbVie, BMS, Pfizer, Gilead, Galapagos, Roche, Sanofi, UCB, Amgen, Sandoz and Novartis. Philippe Dieude: Consultant: BMS, Pfizer, Roche, Chugai, MEDAC, Eli Lilly, Sanofi-Genzyme, Janssen, Boehringer Ingelheim; Unrestricted grant: BMS, Pfizer, Roche, Chugai. José Inciarte-Mundo: received fees from Pfizer, AbbVie, Roche, UCB, Lilly, BMS and MSD for research grant, consultation and/or speaker. JI was an Eli and Lilly Company employee from 2017 to 2019. Marco Sebastiani has nothing to disclose.

Compliance with Ethics Guidelines. This article is based on previously conducted studies and does not contain any new studies with human participants or animals performed by any of the authors.

Data Availability. All data generated or analyzed during this study are included in this published article/as supplementary information files.

Open Access. This article is licensed under a Creative Commons Attribution-NonCommercial 4.0 International License, which permits any non-commercial use, sharing, adaptation, distribution and reproduction in any medium or format, as long as you give appropriate credit to the original author(s) and the source, provide a link to the Creative Commons licence, and indicate if changes were made. The images or 
other third party material in this article are included in the article's Creative Commons licence, unless indicated otherwise in a credit line to the material. If material is not included in the article's Creative Commons licence and your intended use is not permitted by statutory regulation or exceeds the permitted use, you will need to obtain permission directly from the copyright holder. To view a copy of this licence, visit http://creativecommons.org/licenses/by$\mathrm{nc} / 4.0 /$.

\section{REFERENCES}

1. Brito Y, Glassberg MK, Ascherman DP. Rheumatoid arthritis-associated interstitial lung disease: current concepts. Curr Rheumatol Rep. 2017;19(12):79.

2. Cortet B, Perez T, Roux N, Flipo RM, Duquesnoy B, Delcambre B, et al. Pulmonary function tests and high-resolution computed tomography of the lungs in patients with rheumatoid arthritis. Ann Rheum Dis. 1997;56(10):596-600.

3. Turesson C, O'Fallon WM, Crowson CS, Gabriel SE, Matteson EL. Extra-articular disease manifestations in rheumatoid arthritis: incidence trends and risk factors over 46 years. Ann Rheum Dis. 2003;62(8): 722-7.

4. Koduri G, Norton S, Young A, Cox N, Davies P, Devlin $\mathrm{J}$, et al. Interstitial lung disease has a poor prognosis in rheumatoid arthritis: results from an inception cohort. Rheumatology (Oxford). 2010;49(8):1483-9.

5. Suissa S, Hudson M, Ernst P. Leflunomide use and the risk of interstitial lung disease in rheumatoid arthritis. Arthritis Rheum. 2006;54(5):1435-9.

6. Curtis JR, Sarsour K, Napalkov P, Costa LA, Schulman KL. Incidence and complications of interstitial lung disease in users of tocilizumab, rituximab, abatacept and anti-tumor necrosis factor alpha agents, a retrospective cohort study. Arthritis Res Ther. 2015;11(17):319.

7. Vadillo C, Nieto MA, Romero-Bueno F, Leon L, Sanchez-Pernaute O, Rodriguez-Nieto MJ, et al. Efficacy of rituximab in slowing down progression of rheumatoid arthritis-related interstitial lung disease: data from the NEREA Registry. Rheumatology (Oxford). 2020;59(8):2099-108.

8. Vacchi C, Manfredi A, Cassone G, Cerri S, Della Casa G, Andrisani D, et al. Tofacitinib for the treatment of severe interstitial lung disease related to rheumatoid arthritis. Case Rep Med. 2021;2021: 6652845 .

9. Fernandez-Diaz C, Loricera J, Castaneda S, LopezMejias R, Ojeda-Garcia C, Olive A, et al. Abatacept in patients with rheumatoid arthritis and interstitial lung disease: a national multicenter study of 63 patients. Semin Arthritis Rheum. 2018;48(1):22-7.

10. Huang Y, Lin W, Chen Z, Wang Y, Huang Y, Tu SJD, et al. Effect of tumor necrosis factor inhibitors on interstitial lung disease in rheumatoid arthritis: angel or demon? Drug Des Dev Ther. 2019;13:2111.

11. Vassallo R, Matteson E, Thomas CF Jr. Clinical response of rheumatoid arthritis-associated pulmonary fibrosis to tumor necrosis factor-alpha inhibition. Chest. 2002;122(3):1093-6.

12. Kiely P, Busby AD, Nikiphorou E, Sullivan K, Walsh $\mathrm{DA}$, Creamer $\mathrm{P}$, et al. Is incident rheumatoid arthritis interstitial lung disease associated with methotrexate treatment? Results from a multivariate analysis in the ERAS and ERAN inception cohorts. BMJ Open. 2019;9(5):e028466.

13. Wang F, Sun L, Wang S, Davis JM III, Matteson EL, Murad MH, et al. Efficacy and safety of tofacitinib, baricitinib, and upadacitinib for rheumatoid arthritis: a systematic review and meta-analysis. Mayo Clin Proc. 2020;95:1404-19.

14. Fleischmann R, Schiff M, van der Heijde D, RamosRemus C, Spindler A, Stanislav M, et al. Baricitinib, methotrexate, or combination in patients with rheumatoid arthritis and no or limited prior disease-modifying antirheumatic drug treatment. Arthritis Rheumatol. 2017;69(3):506-17.

15. Taylor PC, Keystone EC, van der Heijde D, Weinblatt ME, Del Carmen ML, Reyes Gonzaga J, et al. Baricitinib versus placebo or adalimumab in rheumatoid arthritis. N Engl J Med. 2017;376(7): 652-62.

16. Genovese MC, Kremer J, Zamani O, Ludivico C, Krogulec M, Xie L, et al. Baricitinib in patients with refractory rheumatoid arthritis. $\mathrm{N}$ Engl J Med. 2016;374(13):1243-52.

17. Dougados M, van der Heijde D, Chen YC, Greenwald $M$, Drescher E, Liu J, et al. Baricitinib in patients with inadequate response or intolerance to conventional synthetic DMARDs: results from the RA-BUILD study. Ann Rheum Dis. 2017;76(1): 88-95.

18. Genovese MC, Smolen JS, Takeuchi T, Burmester G, Brinker D, Rooney TP, et al. Safety profile of baricitinib for the treatment of rheumatoid arthritis over a median of 3 years of treatment: an updated 
integrated safety analysis. Lancet Rheumatol. 2020;2(6):e347-57.

19. Combe B, Balsa A, Sarzi-Puttini P, Tony HP, de la Torre I, Rogai V, et al. Efficacy and safety data based on historical or pre-existing conditions at baseline for patients with active rheumatoid arthritis who were treated with baricitinib. Ann Rheum Dis. 2019;78(8):1135-8.

20. d'Alessandro M, Perillo F, MetellaRefini R, Bergantini L, Bellisai F, Selvi E, et al. Efficacy of baricitinib in treating rheumatoid arthritis: Modulatory effects on fibrotic and inflammatory biomarkers in a real- life setting. Int Immunopharmacol. 2020;86: 106748 .

21. Citera G, Mysler E, Madariaga H, Cardiel MH, Castañeda $\mathrm{O}$, Fischer $\mathrm{A}$, et al. Incidence rates of interstitial lung disease events in tofacitinib-treated rheumatoid arthritis patients: post hoc analysis from 21 clinical trials. J Clin Rheumatol Pract Rep Rheum Musculoskelet Dis. 2020.

22. Winthrop KL, Harigai M, Genovese MC, Lindsey S, Takeuchi T, Fleischmann R, et al. Infections in baricitinib clinical trials for patients with active rheumatoid arthritis. Ann Rheum Dis. 2020;79(10): 1290-7. 